\title{
Study on the Complete Movement Arrangement of Rhythmic Gymnastics
}

\author{
Xu Qiong \\ Gymnastics College of Wuhan Institute of Physical Education, \\ Wuhan 430079
}

\begin{abstract}
The thesis many studied the complete movement arrangement of the rhythmic gymnastics in our country through the analysis of the movement connection, apparatus throwing and catching, selection of music, completion capacity and the changes in team formations. Rhythmic Gymnastics is a kind of sports programs that requires the people making natural or rhythmical actions with free hands or with light equipment under the music accompaniment. It is also a women's competitive sports program. Excellent arrangement is of crucial role for the quality of the complete movement of Rhythmic Gymnastics, which is the safeguard for the high artistic value points of the gymnasts in our country. The thesis performed the study of the Rhythmic Gymnastics in our countries in below five aspects including the movement connection, throw and catch of sports equipment, selection of music, completion capacity and the changes in team formations.
\end{abstract}

Keywords-Rhythmic,Gymnastics,Complete Movement, Arrangement

\section{MOVEMENT CONNECTION}

Movement connection refers to the transition movements that used to connect two difficult movements. The difficult movements in complete movement play significant role, however, the connection movements between each two difficult movements would also have significance for the success of the performance. Although the connection movements do not have any difficulty value, they are just like bridges that could organically connect the movements with difficulty values together to demonstrate the harmonious artistic works to the mass, which would ensure the mass would enjoy the unique artistic charming of Rhythmic Gymnastics. For example, in group sports programs, we usually saw the gymnasts running a long distance to achieve the transformation of team formations, while lacking the connection style of small team formations or combinations in the transformation process. The two different connection styles would demonstrate quite different visual effects in the formation transformation process. The one style is demonstrated by the monotonous and dull team form. While the other changes of formation may demonstrate the coherent and smooth process with rich content.

\section{APPARATUS THROWING AND CATCHING}

The apparatus throwing and catching could be divided into individual apparatus throwing and catching and group apparatus throwing and catching. The apparatus throwing and catching is an important indicator for evaluating the arrangement quality of complete movement. It mainly demonstrates the utilization of the spatial layers and the different directions and methods of the throwing and catching of apparatus through the different usage method of apparatus and the diversified changes of the apparatus. Along with the development of the techniques, the evaluation indicators solely limited to the height and distance of the throwing and catching are far from satisfactory. The throwing and catching styles in the Rhythmic Gymnastics in our country are still quite limited and the throwing and catching with low risk would always be the first choice of most gymnasts. The body movement in connection with the equipment lacks novelty. Moreover, the speed of the apparatus movement is still very low and the mastery of movements is still not perfect enough. Besides, the ability of the body parts other than hands and arms still need further strengthening. Below we made a comparison of the throwing and catching techniques between the Rhythmic Gymnastics of China and the Rhythmic Gymnastics of foreign countries based on the analysis of individual apparatus throwing and catching. We selected the individual throwing and catching of rope slings of the top three gymnasts in the 26th World Championship and the National Championship in 2004 to conduct the analysis and statistics.

The analysis of the throwing and catching movements could help us learn about the diversification in times and styles of the throwing and catching, which would not only demonstrate the change relationship of complete movements, but also demonstrate the basic technical skill and mastery status to the apparatus of the gymnasts. In general, the gymnasts in our country would usually take two styles together to complete the movements like non-handing throwing of equipment. However, the excellent gymnasts would generally adapt the three completion styles simultaneously like non-hand throwing and catching of apparatus out of sight. The greatest weaknesses for the throwing and catching of apparatus in our country include the limited throwing and catching styles and limited amount of high and difficult throwing and catching movements. Within them, the throwing and catching out of sight has the largest gap with the foreign countries. Our gymnasts usually failed in completing the required movements for the throwing and catching out of sight. 
TABle I: THE STYleS AND TimeS OF THE THROWING (INDIVIDUAL SPORTS PROGRAM)

\begin{tabular}{|c|c|c|c|c|c|c|}
\hline Type & $\begin{array}{c}\text { Running } \\
\text { Throw }\end{array}$ & $\begin{array}{c}\text { Non-hand } \\
\text { Throwing }\end{array}$ & $\begin{array}{c}\text { Rebound Equipment } \\
\text { During running }\end{array}$ & $\begin{array}{c}\text { Throwing Out } \\
\text { of Sight }\end{array}$ & $\begin{array}{c}\text { None-hand } \\
\text { Throwing }\end{array}$ & $\begin{array}{c}\text { Flexible Throwing } \\
\text { World Championship }\end{array}$ \\
\hline $\begin{array}{c}\text { National } \\
\text { Championship }\end{array}$ & 11 & 3 & 2 & 1 & 6 \\
\hline
\end{tabular}

TABle II: THE StYles AND Times OF THE CATCHING (INDIVIDUAL SPORTS PROGRAM)

\begin{tabular}{|c|c|c|c|c|c|c|}
\hline Type & Running Catch & $\begin{array}{c}\text { Non-hand } \\
\text { Catching }\end{array}$ & $\begin{array}{c}\text { Catch Out of } \\
\text { Sight }\end{array}$ & $\begin{array}{c}\text { Catch Below } \\
\text { Legs }\end{array}$ & Flexible Catching & $\begin{array}{c}\text { Jump and } \\
\text { Rebound } \\
\text { Equipment }\end{array}$ \\
\hline $\begin{array}{c}\text { World } \\
\text { Championship }\end{array}$ & 17 & 6 & 3 & 1 & 3 & 1 \\
\hline $\begin{array}{c}\text { National } \\
\text { Championship }\end{array}$ & 12 & 4 & 1 & 0 & 3 & 1 \\
\hline
\end{tabular}

The group program also has exchange of apparatus as well as the apparatus throwing and catching. The throwing and catching styles of the exchange of apparatus have close relationship with the changes of the team formation in a complement moment. The diversified changes of the team formations would largely depend on the factors like the distance and direction of the throwing and catching of the apparatus. It could be found that there were large amount of throwing and catching and team formations required in one complete moment. However, the coordinated passing, occasional passing within small range, and the occasional changes in team formation and throwing and catching were still quite limited, which resulted in the visual effects that the team moved in the shape like block by block. The prominent changes in the distance, space and position needed further improvement. For example, the lacking of the changes in the height, far distance and short distance of the movements had largely affected the visual impacting effects of the performance. Besides, the failure of the thrown apparatus in reaching certain height also largely reduced the difficulty and breathtaking degree of the throwing and catching of apparatus. The reduction of the technical requirements would serious affect the artistic points of the complete movement.

\section{CHANGES IN TEAM FORMATION (GROUP SPORTS PROGRAM)}

The change of team formation is one of the main constitution elements for the arrangement of group sports programs. Moreover, the change in team formation is also the demonstration of the basic framework of the artistic performance and the theme ideas of complete moments. The selection and application of the changes in formation would largely affect the performance of other aspects of the complete moment. On the application of changes in formation, the strong teams in the world would usually have the features of large amount of changes applied, rapid flowing speed, beautiful formations and perfect integration with the body and apparatus movements, which had demonstrated the high value of the arrangement. The application of changes in formation in our country still lacked innovation ideas and the overall effect fell behind with the strong teams in the world. We had summarized and analyzed the changes in team formation of the top six teams in the National Rhythmic Gymnastics Championship in 2004 and the top six teams in the 28th Olympic Games to provide theoretical basis for the insufficient application of the changes in team formation of complete movement in our country.

TABLE III: SUMMARY FOR THE TEAM FORMATION OF GROUP SPORTS PROGRAM

\begin{tabular}{|c|c|c|c|c|c|}
\hline Contest & Programs & $\begin{array}{c}\text { Effective Team } \\
\text { Formations }\end{array}$ & $\begin{array}{c}\text { Repeat Team } \\
\text { Formations }\end{array}$ & $\begin{array}{c}\text { Transition Team } \\
\text { Formations }\end{array}$ & $\begin{array}{l}\text { Total Team } \\
\text { Formations }\end{array}$ \\
\hline \multirow{2}{*}{$\begin{array}{l}\text { National } \\
\text { Tournament }\end{array}$} & Five Belts & 9.5 & 2.5 & 2.5 & 14.5 \\
\hline & Three rings and two balls & 9.5 & 2.8 & 3.3 & 15.6 \\
\hline \multirow{2}{*}{ Olympic Games } & Five Belts & 10.7 & 3.7 & 2.0 & 16.4 \\
\hline & Three rings and two balls & 11.7 & 3.5 & 2.8 & 18.0 \\
\hline
\end{tabular}

Note: The above figures are the average value of six complete moments.

On the perspective of the change speed and quantity of team formations, each set of movements in a group program in our country generally consisted of 15.1 team formations. Within them, the average quantity of effective team formations, repeat team formation and transition team formations were $9.5,2.7$ and 2.9 respectively. Averagely, one team formation would appear in each 9.7 seconds and one effective team formation would appear in each 15.8 seconds. In the group program of Olympic Games, one complete movement would averagely consist of 17.5 team formations. Within them, the average quantity of effective team formations, repeat team formation and transition team formations were 11.2, 3.9 and 2.4 respectively. On average, one team formation would appear in each 8.5 seconds and one effective team formation would appear in each 13.2 seconds. It could be seen from the summary results (refer to table 3 ) that the application of the changes in team formation of the top six team in the Olympic Games had the features like large quantity, high speed formation, high speed movement, 
high action capacity and high mobility compared with the top six teams of our countries within the same time of 142 seconds for each complete moment. Therefore, the application of team formation in our country still had certain distance with the strong teams in the world on the aspect of speed and quantity.

Compared with the top six teams of Olympic Games, the average quantity of the apparatus exchanges in the established team formations and transition team formations of the top six teams in our country were increased 0.50 times and decreased 2.08 times respectively, which demonstrated that the application capacity in exchanging apparatus and the cooperation techniques among gymnasts during the changing process of team formations had largely fell behind with the top teams in the world. The summary results (refer to table 4) had demonstrated that the top six teams in the Olympic Games could thoroughly use the technical movements of apparatus and cooperation among gymnasts during the changing process of team formation to improve the artistic value of their performance. The artistic value acquired by our team on these two aspects was obviously lower than that of the strong teams in the world.

TABLE IV: Changes IN TEAm Formation AND SELECTION OF MOVEMENT

\begin{tabular}{|c|c|c|c|c|c|}
\hline Contest & $\begin{array}{c}\text { Classification of Team } \\
\text { Formation }\end{array}$ & Body Difficulty & $\begin{array}{c}\text { Application of } \\
\text { Apparatus }\end{array}$ & $\begin{array}{c}\text { Exchange of } \\
\text { Apparatus }\end{array}$ & $\begin{array}{c}\text { Cooperation Among } \\
\text { Gymnasts }\end{array}$ \\
\hline \multirow{2}{*}{$\begin{array}{c}\text { National } \\
\text { Tournament }\end{array}$} & $\begin{array}{c}\text { Established Team } \\
\text { Formation }\end{array}$ & 7.66 & 3.16 & 5.25 & 0.74 \\
\hline & $\begin{array}{c}\text { Transition Team } \\
\text { Formation }\end{array}$ & 1.66 & 3.75 & 0.58 & 3.91 \\
\hline \multirow{2}{*}{ Olympic Games } & $\begin{array}{c}\text { Established Team } \\
\text { Formation }\end{array}$ & 7.37 & 3.83 & 4.75 & 1.25 \\
\hline & $\begin{array}{c}\text { Transition Team } \\
\text { Formation }\end{array}$ & 1.74 & 5.66 & 2.66 & 6.16 \\
\hline
\end{tabular}

Note: The above figures are the average value of six complete moments.

On the aspect of the changing method of the team formations, the quantity gap between the teams of our country and the top six teams in the Olympic Games in the synchronized changes of team formation for same movements and different movements was +5.59 and -0.33 respectively. However, the quantity gap in the same movement and different moments during the changing process of team formations was -3.00 and -3.92 respectively. The changes of different team formations are the most important parts in demonstrating the team formation effect of group program of Rhythmic Gymnastics. It could be seen from the above analysis that the teams in our country adapted too many synchronized changes of team formations, while legged behind with the top teams in the world on techniques of asynchronous team formation changes. The summary results are shown in table 5 .

TABLE V: SUMmARY FOR THE CHANGE METHODS OF TEAM FORMATION

\begin{tabular}{|c|c|c|c|c|c|c|c|c|c|c|}
\hline \multirow[b]{2}{*}{ Contest } & \multicolumn{5}{|c|}{ Synchronized Changes } & \multicolumn{5}{|c|}{ Asynchronous Changes } \\
\hline & $\begin{array}{c}\text { Same } \\
\text { Direction }\end{array}$ & $\begin{array}{c}\text { Same } \\
\text { Moveme } \\
\text { nt }\end{array}$ & $\begin{array}{l}\text { Same } \\
\text { Level }\end{array}$ & $\begin{array}{c}\text { Multi-as } \\
\text { pect }\end{array}$ & $\begin{array}{c}\text { Multi-mo } \\
\text { vement }\end{array}$ & $\begin{array}{c}\text { Same } \\
\text { Direction }\end{array}$ & $\begin{array}{c}\text { Same } \\
\text { Moveme } \\
\text { nt }\end{array}$ & $\begin{array}{l}\text { Same } \\
\text { Level }\end{array}$ & $\begin{array}{c}\text { Multi-as } \\
\text { pect }\end{array}$ & $\begin{array}{c}\text { Multi-mo } \\
\text { vement }\end{array}$ \\
\hline $\begin{array}{c}\text { National } \\
\text { Tournament }\end{array}$ & & 26.58 & & & 7.83 & 1.58 & & & 14.91 & 50.90 \\
\hline Olympic Games & & 20.99 & & & 8.16 & 4.58 & & & 18.83 & 52.56 \\
\hline
\end{tabular}

Note: The above figures are the average value of six complete moments.

As for the graphics selected, the group programs in our country did not have any significant differences with the top six teams in the Olympic Game, both of which had selected more regular graphics more irregular graphics. However, the graphics selected by China team in the transition team formation and reappearing team formation were much more than those of the teams from the Olympic Games. The summary results are shown in table 6.

TABLE VI: SUMMARY LIST FOR THE GENERALLY USED TEAM FORMATIONS

\begin{tabular}{|c|c|c|c|c|}
\hline Contest & Straight Line Shape & Round Shape & Cross Shape & 7 \\
\hline National Tournament & 7 & 11 & 6 & 7 \\
\hline Olympic Games & 8 & 8 & 16 & 7 -Shaped \\
\hline
\end{tabular}

In the championship, the quantity of supporting team formations generated for the exchanges of apparatus and the quantity of transition team formations generated during the changing process of two big team formations was 46 and 23 respectively. However, the quantity of supporting team formations and transition team formations was 44 and 17 respectively.

\section{COMPLETION CAPACITY}

The complete capacity shall refer to the quantity of actions completed within the unit time during the process 
of one complete movement. The complete capacity consists of the complete capacity of body actions and the complete capacity of the actions of apparatus, which is a crucial indicator to evaluate the speed and rhythm of one complement movement of gymnasts. Based on the current development level, the complete capacity is one of the problems that could not be ignored. Complete capacity is the guarantee for us to reach and exceed the world level because the lower quantity of the complete capacity would increase the class level of the difficult movements. However, higher quantity of complete capacity would increase the error rate. It could be seen from the development layout of the rhythmic gymnastics that the quantity of the complete capacity for the gymnasts in our country is largely lower than that of the quantity of complete capacity of the gymnasts at the world leading level. The study selected the operation actions of the top six gymnasts in the National Rhythmic Gymnastics Championship in 2004 and the top six teams in the 28th Olympic Games as the analysis object. The specific data was shown in table 7 . In order to surpass the international level of Rhythmic Gymnastics, the guarantee in quantity is the first priority. In case the quantity is less than the opponents, the excellent results could only be achieved through the increasing of the movement difficulty. However, high difficulty also means the high completion risk, which may result in the situations of loss outweighing the gain once failing in completing the movement. Excess quantity may be not catering for the actual situation of the gymnasts, which would also affect the amplitude and integrity of the movement.

TABLE VII: COMPARISON LIST FOR THE COMPLETE CAPACITY OF CLUBS BETWEEN THE GYMNASTS IN CHINA AND TOP GYMNASTS IN THE WORLD

\begin{tabular}{|c|c|c|}
\hline & Top Gymnasts in the World & Gymnasts in China \\
\hline Complete Capacity of Body Movement & About 60 50 \\
\hline Complete Capacity of Apparatus Movement & About 65 & About 55 \\
\hline
\end{tabular}

\section{MUSIC}

It could be seen from the Code of Points for International Gymnastics that music is one of the indispensable element for Rhythmic Gymnastics. In 1976, the International Federation of Gymnastics put forward the basic principles for the music accompaniment for the first time in the amended Code for Points for Rhythmic Gymnastics. The latest Code requires that the complete movement must be completed under the music accompaniment. Only extreme short pausing of music is allowed in case of the requirement of arrangement. Between 1.0 and 1.5 points would be deducted from the total points achieved if pausing of music happened during the process of the complete movement. The final point would be zero if music accompaniment is not used or is not used for quite a long time. In case the complete movement is completed before the completion of the music, 0.3 points would be deducted. The final points would also be deducted 0.3 points if the movement is not perfectly match with the music. The above point deduction rules demonstrate the importance of music accompaniment in the Rhythmic Gymnastics. From the domestic and international competitions, the universal opinion of the experts from both home and abroad was that the gymnasts in China had poor understanding for the connotation of music works and poor artistic performance ability. The thesis found the music of Rhythmic Gymnastics in our country had below problems through the searching and summary of related documents:

The first problem was that the rhythm of music could not perfectly match with the rhythm of movement. The Code of Point for Rhythmic Gymnastics specifies that movement and music must be a harmonious and integrated part. The rhythm of music accompaniment for Rhythmic Gymnastics has close relationship with the rhythm of movement. We found the coach and gymnasts in China had ignored the importance of the improvement of music knowledge and the cultivation of inner hearing ability for music to the understanding of the connotation of music works, which had resulted in the poor performance of the individual feeling and the inner passion. Therefore, they could not reflect the perfect integration between the body language and music language, and could not highlight unique features and artistic image of the performance of Rhythmic Gymnastics. Through the statistics and analysis, teacher Gou Xioya came to the conclusion that our gymnasts have significant differences with the excellent gymnasts in the world on this aspect, especially for the performance with clubs and belts. Due to the difference in different apparatuses, the ability of the gymnasts in completing movements also has significant influence to the matching degree between the rhythm of movement and the rhythm of music.

Second, the selection of music in our country still needed further improvement. Although our country had also produced some excellent music during competition, the low quality music would usually appear in the contest field. Editing and cutting were the most generally used approach for the production of music in our country. The key factor for the success of music produced with such approach is to integrate the different music selected into an organic and harmonious integrity. The actual situations, however, were that most of the music produced had disharmony styles among different sections. Most of the music was carelessly produced without reflecting the ideological implications of the music. Therefore, the low quality of the music is surprising.

\section{REFERENCES}

[1] Zhang Ce, Tang Yanping, Wang Hexia, Zhao Henghe [J]. Journal of Beijing Sport University. The status quo of the development of the sports dance curriculum in Colleges and universities in China. 2009 (09)

[2] Ni Xin, Ye Wei. Analysis of additional sports dance teaching in college physical role [J]. sports and science. 2006 (03) 
[3] Jiang Wei, Jia Baojian. Physical education in public colleges and universities offering the physical dance course examines [J]. Journal of Beijing Sport University. 2006 (10)

[4] Zhang Yan. Group counseling on mental health of college students to study the effect of [J]. training talents. 2011 (20)

[5] Xie Zhijing, Tang Qiuping, Chang Xianlu, Deng Yunlong. 457 college students psychological abuse and neglect in childhood experiences and mental health [J]. Chinese Journal of clinical psychology. 2008 (01)

[6] Li Xiangru. Study on the Education Practice Reform of the Higher Physical Education in Our Country [J]. Journal of Guangzhou Physical Education College, 2001, (6)

[7] Ba Yanfang, Guo Min. Study on the Construction of Physical Education Practice Bases under the New Situations [J]. Journal of Chengdu Education Institute, 2005 (10)
[8] Xu Shengxia, Guo Min. Exploration for the Construction of Physical Education Practice Bases under the New Situations [J]. Journal of Capital Institute of Physical Education, 2005.

[9] Ziwang Chen. Research on current situation and Countermeasures of [J]. Journal of Beijing Sport University of China's sports departments of universities sports dance courses. 2006 (02)

[10]Zuo Chunyu. Meta cognition on the significance of [J]. in the mental health of college students of Shanxi Youth Management, 2011(02)

[11] Xu Gaohou. Education Practice [M]. Beijing: Beijing Normal University Press, 1995

[12] Gao Zhi, Chen Xingsheng, Xu Qiong, Du Congxin, Zhai Huanan, Wang Yufeng. Study on the Reform of the Education Practice for Physical Education [J]. Journal of Wuhan Physical Education College. 2002, (4) 